\title{
Outside the classroom: the participatory design workshop on Healthy City, Mixco, Guatemala
}

\author{
Giofrè, Francesca ${ }^{a}$; Ramírez de León, Mario Raúl ${ }^{\text {b }}$
}

${ }^{a}$ Department Planning Design Technology of Architecture, Sapienza University of Rome, Italy, ${ }^{b}$ Department of Architecture, University of San Carlos of Guatemala, Guatemala.

\begin{abstract}
The paper describes an innovative teaching experience held at the Faculty of Architecture at the University of San Carlos of Guatemala as part of the Professional Practice Program (Ejercicio Profesional Supervisado - EPS). 20 students and 9 professors, coordinated by 4 professors, carried out a workshop on the theme of Healthy City in the Municipality of Mixco, with the support of the same. Through active learning, a 'depravity' of the teaching activity and a participatory confrontation activity through interviews and questionnaires with citizens and stakeholders, the students and professors worked in 4 groups for seven days creating a community of practice. The results took the form of project proposals aimed at urban regeneration, in accordance with the principles of the Healthy city, presented to the local community and to the Municipality of Mixco. The experience can be repeated in its methodology and has been positively evaluated by all the participants in terms of acquisition of competences to dialogue with citizens and stakeholders for the identification of needs, increase in design skills and group work, as well as provide a real service in the area. The future urban planners and architects have also played a new role as mediators of participatory processes and facilitators stakeholders to raise needs, increase project skills and group work, as well as of real service on the territory. The future urban planners and architects have also played a new role as mediators of participatory processes and facilitators.
\end{abstract}

Keywords: Learning in Higher Education; Architecture; Healthy City; Participatory Design; Urban Regeneration. 


\section{Introduction}

During the second semester of 2017 between the Faculty of Architecture of Sapienza University of Rome, Italy, and University of San Carlos of Guatemala (USAC), a participatory design workshop on Healthy cities was developed, with the collaboration of the Municipality of Mixco, Guatemala.

The workshop aimed to provide a new project and teaching methodology to students, outside the classroom, based on the collection of the real needs of citizens, and aimed at establishing the perception of the population in mid and small urban areas, as exemplar of the meaning, perception and characteristics of a healthy city. The key categories studied correspond to the state of the art in urban planning and health: public space, transportation, risk, infrastructure, recreation, among others.

A qualitative, participatory research model was employed, with the participation of 20 students of the Ejercicio Profesional Supervisado (EPS). The EPS is a six-month period that students at the Faculty of Architecture develop in the country side of Guatemala, after completing five years of studies. It is part of the social compromise of USAC, with the purpose to link theory with practice in real life situations.

Students were accompanied by nine teachers of the EPS, and four professors acting as coordinators.

In preparation for the workshop, a first questionnaire using google forms was sent to the email of the employees of the Municipality of Mixco, to acquire a general background of the situation in Mixco, regarding the key issues of healthy cities. Also, the Municipality provided a set of maps of the city, with the location of the different neighborhoods, green areas, basic infrastructure, among other urban features.

With this information, the workshop started with a two days general meeting with students and professors, where the key theoretical issues were addressed, as well as the participatory model of the workshop. During this phase, the Urban Planning director of Mixco, was invited to give an overview of the City of Mixco.

The third day, students began field activities, making interviews with stakeholders and local authorities, followed by a survey, to a random sample of 200 citizens of Mixco. Students were divided into four groups, to ensure the maximum coverage of the Historic Center of Mixco (HCM). Each group had to investigate a specific aspect of HC, making different routes through the different barrios (neighborhoods) of Mixco: El Cenicero, El Cementerio, Pansalic, Siguiche, El Cerrito, El Progreso. through the different barrios (neighborhoods) of Mixco: El Cenicero, El Cementerio, Pansalic, Siguiche, El Cerrito, El Progreso. 
The results have been positively evaluated in terms of didactic innovation and the possibility of repeating the methodology to other contexts of the Country both by students and by teachers. The data analysis shows, also, that there is a polarization in Mixco, where most of the respondents from Pansalic and El Cerrito show a positive correlation between the perception of public space, transportation, risk, and infrastructure, even though there are no green areas of significance in those neighborhoods.

\section{Background}

The XX century has been dominated by positivist educational theories. Ashraf Salama (1995) has made a profound study on the different approaches in architectural education, while Diana Cheng (2001) has analyzed the transition between a modernist and postmodernist approach in education, identifying Tyler as a representative of positivism in modernity, where education was based in educational objectives.

Moreover, Salama identifies the main trends in architectural education during the $\mathrm{XX}$ century, which are, among others: The experimental model of Martin Symes and Alexi Marmot; the energetic conscious model of Raymond Cole; the analogical model, Gordon Simmons; the participative model, Henry Sanoff. The last one, the participatory model, begins at the end of the 1960's. Sanoff states that: "Participatory design is an attitude about a force for change in the creation and management of environments for people. Today participatory design processes are being applied to urban design and planning as well as to the fields of industrial and information technology" (Sanoff, 2007). This social consciousness, therefore, has been growing in design disciplines. Its techniques and methods, usually involve interviews, workshops, questionnaires, and surveys, among others. Sanoff states that: "Architecture in the future should be characterized by an increasing participation of the user in its organizational and formal definition. In order to respond to this situation, professionals will need to do everything possible to make design solutions less the representation of its designers and more the representation of its users." (Sanoff, 1988).

Knowing this, the topic that was chosen to work in the workshop was that of Healthy City, which has evolved over time at the level of world policies that give European importance to the design of the environment in urban settings (Giofrè, Djukanovic, 2017).

The Healthy City (HC) is a set of guides and recommendations, regarding the benefits of a good urban environment. It follows the aims and objectives of the United Nations (UN) first, the Objectives of the Millenium, and its successors, the Objectives of Sustainable Development, specially, the results of the UN-HABITAT meetings (World Health Organization, 2011) and the so-called “Zagreb declaration”(World Health Organization, 
2009). The Healthy urban planning "means planning for people. It promotes the idea that the city is much more than buildings, streets and open spaces, but a living, breathing organism, the health of which is closely linked to that of its citizens" (Barton \& Tsourou, 2013, p. i). HC has favored the participatory process envisioned by Sanoff at the end of the $\mathrm{XX}$ century, as part of UN initiatives:

"the effect of the built environment on health, ..., was highlighted that healthy urban planning covers several levels of urban planning and the provision of basic requirements like shelter, clean water, sanitation and access to food, and quality of life projects such as new parks and bicycle lanes. Another key element was the need in healthy urban planning to think and practice in an interdisciplinary fashion. This means using active community participation - not only involving different sectors, but also property owners, development entities, and urban residents." (World Health Organization, 2011, p. 3).

The intervention area chosen for the workshop was the municipality of Mixco; with an area of about $99 \mathrm{~km} 2$ and a population of 483.705 inhabitants (Instituto Nacional de Estadística, 2014), makes, with its neighbor Guatemala City, and Villanueva, an urban area of about five million people, the biggest urban area between Mexico City and Medellin in Colombia (Smith, 1988). In this study, we will concentrate on the historic center of Mixco (Fig.1), with a surface area of $1.37 \mathrm{~km} 2$, and a population, according to the population density of Mixco of 4.200 inhabitants, as a case study.
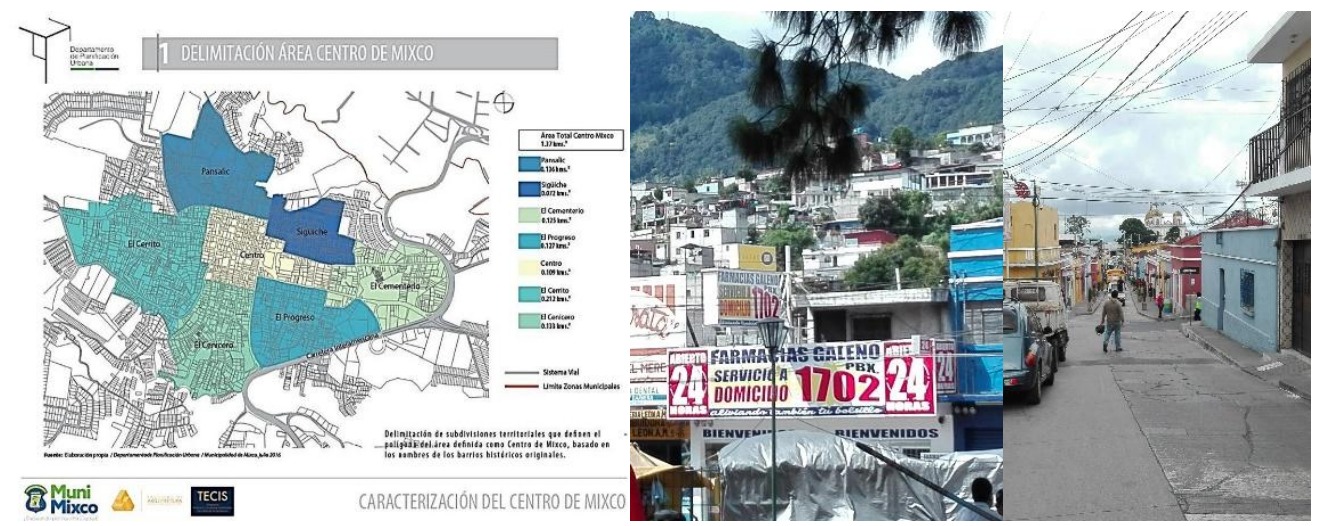

Figure 1. The six neighborhoods of Mixco, Municipalidad de Mixco (2017)

With these premises and with this specific topic, the Faculty of Architecture of Sapienza University of Rome and University of San Carlos of Guatemala, have experimented an innovative didactic methodology in favor of students and professors, proposing concrete project ideas to the Municipality of Mixco. 


\section{Methods and materials}

A qualitative, participative research model was employed, with the participation of 20 students of the Ejercicio Profesional Supervisado (EPS), and the supervision of 9 teachers of USAC, and 4 teachers as coordinators, 1 from Sapienza University of Roma and 3 form USAC.

After sharing the workshop program with EPS professors, to collect impressions and to review the activities, the EPS students were gathered to develop a five-day workshop. The structure of the workshop was developed as follows:

- The first two days were dedicated to establish the theoretical framework of HC, making conferences and discussion groups where students began to acquire the basic knowledge on the subject of HC. The conferences have addressed the following objectives and topics: Healthy city and architecture; A methodology of work on Healthy City; Territorial information System, its application and importance in urban planning; Case Study the City center of Mixco; Urbanism and resilience; The interview as a research technique; Healthy city and urbanism principles. At the end of the conferences, the results of the questionnaire to the employees of the Municipality of Mixco were shown to students and professors. The activities were developed at the facilities of the Faculty of Architecture, USAC, in Guatemala City. After the conferences, students were then divided in four groups, corresponding to the following key categories of analysis: Public spaces; infrastructure; risk; transportation and have begun to work in groups simulating the interviews that were going to make to the citizens.

- In the following three days the whole task group has moved to the Municipality of Mixco, where the activities began with free interviews to key stakeholders. The purpose of the interviews was to acquire an understanding of the critical aspects of the territory, and then, divided in groups, the students have interviewed, with the aid of a structured questionnaire adjusted by the coordinators, a random sample of 200 citizens of Mixco, who inhabit six neighborhoods around the city center: El Cenicero, El Cementerio, Pansalic, Siguiche, El Cerrito, El Progreso. The questionnaire to the citizens was made in printed format, but later, students transferred the responses to the Google forms software, with the objective of reading the data comparatively.

- With the data and the results of the interviews and questionnaires, students, accompanied by their teachers, have developed project ideas that have been presented first to the Municipality of Mixco, and later, to the entire group of EPS students at USAC in Guatemala City (Fig.2). 


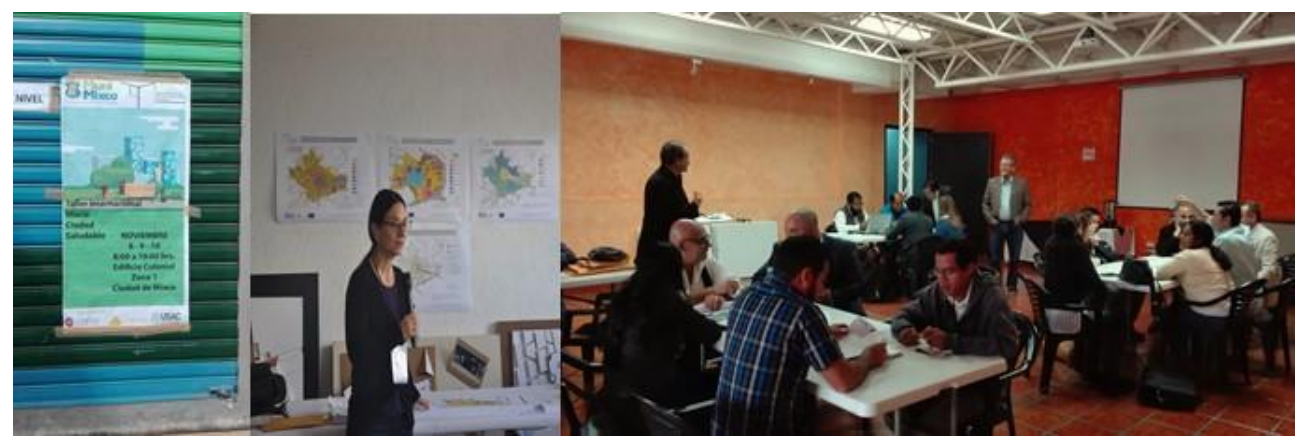

Figure 2. Workshop activities in City of Guatemala and in the Municipality of Mixco (2017)

\subsection{The questionnaires}

The questionnaire to the employees of the Municipality of Mixco, was sent directly to the institutional mail of Mixco. The data was then processed online, with the google form platform, so that it was possible to have an insight of the critical aspects in the city center of Mixco, before the workshop started, and for the preparation of the questionnaire to the citizens.

The questionnaires applied to citizens by the students of EPS, explored the four main categories described above, and has been structured in five parts, as follows:

- The first part "General aspects" structured in four questions that give an overview of the participants, the so-called "demographic module" of the questionnaire (sex, age group, place of residence, work and study) and closes with a direct question: the city of Mixco is perceived as a healthy place to live?

- The following four parts are articulated around the main categories of analysis: public space, urban mobility, risk, urban equipment and public services.

- The final part asks the interviewed, to indicate, in a scale from 1 to 10 which of the four key aspects objective of the research are the more critical aspects, and a last and final open question: If you were the city Major of Mixco what would you do? What would be your priority to regenerate the city?

The students, apart from the printed questionnaire have in hand a city map with the area of research, this, to aid the citizens in the lecture of the territory and in the identification of the critical aspects.

At the end of the questionnaires, each group of students could upload the answers of each people surveyed, using the Google forms software. 
With the data, in a comparative way, students, always divided in groups have developed project solutions, as an answer to the needs identified by the citizens, the people interviewed, the stakeholders, and even before, the questionnaires to the employees of the Municipality of Mixco.

The results of the workshop were presented by the students first, to the local Municipality in Mixco and, then, after one more day of work, the proposals, were presented at the USAC to other EPS students and professors to share not only the results but the work methodology (Fig.3).

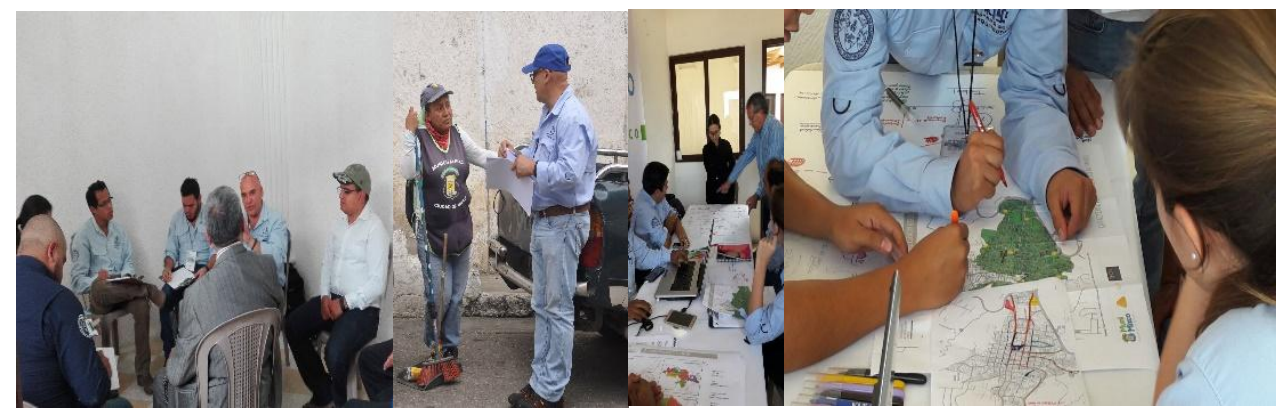

Figure 3.Interviews and design work, Municipality of Mixco (2017)

\section{Results}

The experimental workshop shows that it is desirable to develop a participative process in a higher education environment, particularly, in architecture and urbanism. Students were interested in the methodology and showed interest in the completion of the task. Assigned and working outside the classroom, in contact with the local community, feel more motivated and involved. Even the professors who have worked with this methodology for the first time have recognized their potential in terms of increasing the number of students.

The workshop, through active learning, a 'depravity' of the teaching activity and a participatory activity, creates a community of practice with the aim of producing organized and quality knowledge in terms of design.

The experience described has been of short duration and experimental in nature. We have to take into account that participatory processes require longer times. The limit of such processes is the effective transfer of the results to the community, in terms of the realization of the proposed interventions, this aspect is, however, linked most of the time to political decisions, and to the possibility of funding.

We can conclude that in the participatory processes, urban planners and architects play a new role as mediators and facilitators of implementation processes. Thus, a new role for 
architects is emerging, out of the traditional academic programs run by faculties of architecture around the world.

\section{References}

Barton, H., \& Tsourou, C. (2013). Healthy Urban Planning. Taylor \& Francis. Retrieved from https://books.google.com.gt/books?id=MaJRDbX_8-oC

Cheng-Man Lau, D. (2001). Analysing the curriculum development process: three models. Pedagogy, Culture \& Society, 9(1), 29-44. https://doi.org/10.1080/14681630100200107

Giofrè F., Djukanovic Z. (2017). Healthy urban environment and design: the outdoor spaces. In: Book of Proceedings Keeping up with technologies in the context of urban synergy Place and technologies 2017. pp. 155-168, Sarajevo:CIP, ISBN: 9789958691560, Sarajevo, 8-9 giugno 2017

Instituto Nacional de Estadística. (2014). Caracterización departamental de Guatemala. Guatemala.

Salama, A. (1995). New trends in architectural education, designing the design studio. Raleigh.

Sanoff, H. (1988). Participatory Design in Focus. Architecture and Behaviour, 4(1), 24-42.

Sanoff, H. (2007). Multiple views of participatory design. International Journal of Architectural Research, 2(1), 57-69.

Smith, G. (1988). Guatemala, a fragile democracy. National Geographic, 173(6), 768-803.

World Health Organization. (2009). Zagreb Declaration for Healthy Cities. Zagreb. Retrieved http://www.euro.who.int/_data/assets/pdf_file/0015/101076/E92343.pdf

World Health Organization. (2011). Healthy Urban Planning. Report of a Consultation Meeting. Kobe. 